\title{
Economic and environmental assessment of solar cooling systems
}

\author{
I. Amlal, A. El Fadar \\ Laboratory of Innovating Technologies \\ National School of Applied Sciences, Abdelmalek Essaadi University \\ Tangier, Morocco \\ smailam460@gmail.com \\ aelfadar@uae.ac.ma
}

\begin{abstract}
The objective of this work is to investigate the main solar cooling systems, namely photovoltaic (PV) and thermal sorption (absorption and adsorption) systems, in order to identify the most cost-effective technology according to operating and climatic conditions. A technicoeconomic and environmental comparison has been carried out through a case study. The results revealed that the conventional system powered by photovoltaic panels represents the most appropriate choice in terms of annual cold production and levelized cost of energy (LCOE) when compared with the adsorption and absorption systems, but in terms of environmental aspect the choice of the latter systems is more judicious.
\end{abstract}

Keywords-Solar cooling; Absorption; Adsorption; Conventional cycle; Photovoltaic; LCOE; GHG emissions

\section{INTRODUCTION}

The intensive use of fossil fuels (oil, gas, coal, etc.) for nearly 150 years placed humans today in a dual context: the increase in the greenhouse effect with catastrophic climatic consequences, and the predictable exhaustion of these sources of energy from the underground. Indeed, global reserves of oil, natural gas and coal are estimated at about 40, 61 and 227 years respectively [1]. The importance of improving thermal comfort in buildings has led to the large-scale implementation of HVAC (heating, ventilation and airconditioning) systems, which has resulted in an increase in the building's energy consumption. It is therefore crucial to identify and use cost-efficient and friendlyenvironmental HVAC systems in order to reduce building energy consumption and carbon emissions.

In the field of refrigeration, cooling systems are currently numerous and varied and their operating principle remains however the same; it is based on extracting a quantity of heat from a cold source and injecting a quantity of heat to a hot source at higher temperature level [2].

Besides, the use of solar energy is one of the promising solutions, especially in non-electrified regions where solar radiation is abundant, since the need for air conditioning and refrigeration generally matches with the availability of solar resources $[3,4]$. In this regard, there are two basic approaches to produce cold with solar energy. The first approach is based on photovoltaic effect by using PV cells, a direct conversion of solar energy into electricity that can be used to operate a conventional compression cycle.
The second one is to convert solar rays into heat at a relatively high temperature, then use it to increase the temperature and pressure of the refrigerant. This approach, called sorption refrigeration, is based on wellestablished thermodynamic principles. In this case, the refrigerant undergoes four thermodynamic transformations (compression, condensation, expansion, evaporation), the main difference between absorption, adsorption and conventional compression systems lies in the way in which the refrigerant is compressed, see Fig. 1. During condensation and evaporation, the refrigerant changes its phase liquid/vapor.

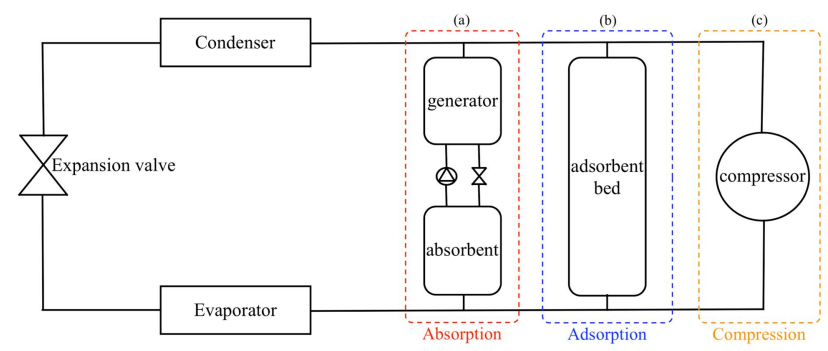

Figure 1. Schematic diagram of the main cooling systems with different compressors.

\section{CASE STUdY}

The goal of this section is to carry out a comparative study of three cooling systems in order to identify, for the same annual cold needs and operating conditions, the most appropriate cooling technology, (i) economically in terms of levelized cost of energy (produced cold), (ii) technically in terms of coefficient of performance and (iii) environmentally by estimating the greenhouse gas (GHG) emissions.

For this aim, we chose a building located in the Tangier city, Morocco, with a latitude of $35.76^{\circ} \mathrm{N}$ and a longitude of $5.79^{\circ} \mathrm{W}$. On other hand, the cooling needs can be calculated based on the dimensions, location of the house and on characteristics of the building materials. In the current case study, the building has an area of $151.75 \mathrm{~m}^{2}$ and a roof height of $2.8 \mathrm{~m}$. Table I shows the detailed data of building dimensions. The chosen comfort temperature is $22^{\circ} \mathrm{C}$ for the summer and the global thermal resistance of the building including lateral walls and windows is $0.38 \mathrm{~m}^{2} . \mathrm{K} \cdot \mathrm{W}^{-1}$. 
TABLE I. CHARACTERISTICS OF THE PROPOSED BUILDING

\begin{tabular}{|c|c|c|c|c|}
\cline { 2 - 5 } \multicolumn{1}{c|}{} & $\begin{array}{c}\text { Length } \\
(\mathbf{m})\end{array}$ & $\begin{array}{c}\text { Width } \\
\mathbf{( m )}\end{array}$ & $\begin{array}{c}\text { Height } \\
\mathbf{( m )}\end{array}$ & Surface $\left(\mathbf{m}^{\mathbf{2}}\right)$ \\
\hline Room 1 & 5 & 4 & 2.8 & 20 \\
\hline Room 2 & 5 & 4 & 2.8 & 20 \\
\hline Kitchen & 9.5 & 5.5 & 2.8 & 52.25 \\
\hline Living room & 9.5 & 5 & 2.8 & 47.5 \\
\hline Bathroom & 4 & 3 & 2.8 & 12 \\
\hline
\end{tabular}

The annual cooling energy requirements are calculated using the following formula:

$$
E=24 \times G \times D j \times V
$$

where $G$ is the total heat losses per volume unit $\left(\mathrm{W} / \mathrm{m}^{3} .{ }^{\circ} \mathrm{C}\right)$ corresponding to the difference between outside temperature and the comfort temperature; $\mathrm{V}$ is total volume of building $\left(\mathrm{m}^{3}\right)$ and $\mathrm{Dj}$ is the cooling number of degree-days $\left({ }^{\circ} \mathrm{C} /\right.$ day) [5]:

$D j=\sum_{i=1}^{p}\left(T_{c}\right)_{i} \quad\left\{\begin{array}{c}\text { if } T_{m}>T_{\text {ref }} \text { then } T_{c}=T_{m}-T_{\text {ref }} \\ \text { else } T_{c}=0\end{array}\right\}$

where $T_{\text {ref }}$ represents the reference temperature; $T_{m}$ is mean daily air temperature; $T_{c}$ denotes daily number of degree day and $\mathrm{p}$ is the period of time (number of days).

The division of equation (1) by the coefficient of performance (COP) of each system gives the amount of electrical energy consumed by the vapor compression cooling system (VCC) and the amount of thermal energy consumed by sorption systems (absorption and adsorption).

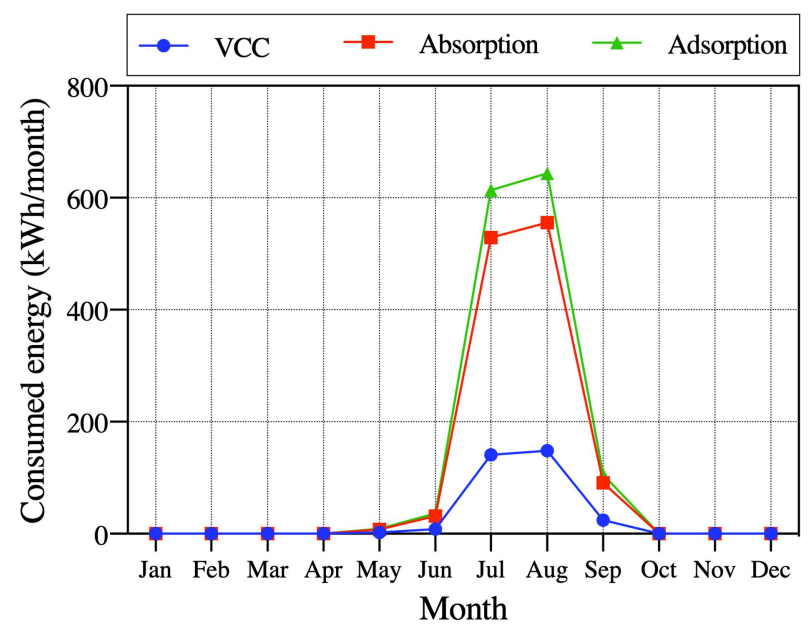

Figure 2. Variation of the monthly energy consumed by the studied systems [6].

Figure 2 represents the variation of the monthly cooling energy consumed by the studied systems. the maximum cold demand is significant during the month of August, which gives a monthly cooling energy of $148.61 \mathrm{kWh} /$ month, $555.39 \mathrm{kWh} /$ month and 643.93 $\mathrm{kWh} /$ month for vapor compression system, absorption and adsorption systems respectively.
The technical dimensioning of photovoltaic panels (PV) is based on the choice of their maximum peak power in the cooling period which is given by the following formula:

$$
P_{c}=\frac{E_{c}}{G_{\beta} \times \eta_{r}}
$$

where $E_{c}$ is energy consumed $(\mathrm{kJ})$ during the daily operating time which is assumed by 6 hours, $G_{\beta}$ is the irradiation received by a surface with a tilt angle of $\beta$ and $\eta_{r}$ is the losses coefficient of PV panel.

In our case $P_{c}=1284 W_{c}$; the division of this value by the power production of one panel which is $360 \mathrm{~W}$ gives a number of 4 panels by a single cooling unit.

The sizing of sorption systems (absorption and adsorption) is based on the choice of the minimum irradiation to determine the maximum surface area of evacuated tube collectors required to produce hot water at a temperature of $95{ }^{\circ} \mathrm{C}$ during the cooling period.

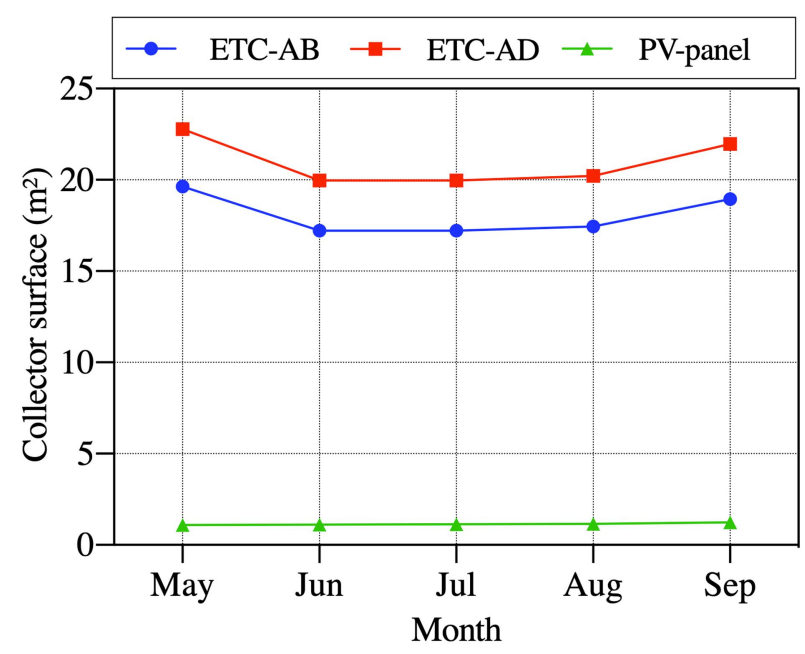

Figure 3. Collectors surface variation during the cooling period.

Fig. 3 shows the variation of the collectors' surface area required to operate the solar cooling systems during the summer period. It can be seen that the evacuated tube collectors feeding the adsorption system have an average surface area of $20.98 \mathrm{~m}^{2}$ which is greater by $13.77 \%$ than evacuated tube collectors surface driven the absorption system and by $94.5 \%$ than the PV panel surface of vapor compression.

\section{A. ECONOMIC INDICATORS}

The most significant economic indicators are the levelized cost of energy (LCOE) and the payback period PP.

- Levelized cost of energy:

$$
L C O E=\frac{(C C \times F C R)+M}{E}
$$

where $C C$ represents the capital cost including the installed cost; $M$ is the annual operational and maintenance costs; E is the annual cold, and FCR is the 
fixed charge rate, it is a factor that includes financing, tax and inflation considerations.

- $\quad$ Payback period (PP):

$$
\text { Payback period }=\frac{\text { Total Investment }}{\text { Annual cash inflow }}
$$

\section{B. ENVIRONMENTAL INDICATORS}

The evaluation of GHG emissions is corresponding to the amount of $\mathrm{CO}_{2 \text {-eq }}$ emitted during the operation of cooling equipment over its lifetime [7]; it is given by the following formula:

$$
G H G=G H G_{\text {direct }}+G H G_{\text {indirect }}
$$

The former term is due to refrigerant leaks, whereas the latter is due to $\mathrm{CO}_{2}$ emissions associated with the process of electricity generation [8] and the manufacturing.

$$
G H G_{\text {direct }}=G W P(L \times n+m(1-\alpha))
$$

where GWP is the global warming potential measured by units of carbon dioxide equivalents (expressed in $\mathrm{kg}_{\mathrm{CO}_{2-\mathrm{eq}}} / \mathrm{kg}_{\text {refrigerant }}$ ) [9], $\mathrm{L}$ is the annual leakage rate for the systems $\left(\% \mathrm{~kg}_{\text {refrigerant }} /\right.$ year $), \mathrm{n}$ represents the operating time (year), $\mathrm{m}$ is the refrigerant charge $\left(k g_{\text {refrigerant }}\right)$ and $\alpha$ is the recycling factor $(\%)$.

$$
G H G_{\text {indirect }}=E \times \beta \times n+G H G_{M}
$$

where $\mathrm{E}$ is the annual energy consumption $(\mathrm{kWh} /$ year), $\beta$ is $\mathrm{CO}_{2}$ emissions factor $\left(\mathrm{kg}_{\mathrm{CO}_{2}} / \mathrm{kWh}\right)$ and $G H G_{M}$ is the emissions associated to the manufacturing process.

It is assumed that the recycling factor of R134a is $95 \%$, the annual leakage value is $20 \% \mathrm{~kg}_{\text {refrigerant }} /$ year [10], $\beta$ is evaluated to be $0.718 \mathrm{~kg} C_{2-e q} / \mathrm{kWh}$ for Morocco [11] and the annual emissions factor of photovoltaic panels is $0.32 \mathrm{~kg}_{\mathrm{CO}_{2}} / \mathrm{kWh}$ [12].

It should be noted that $\mathrm{n}$ is corresponding to the total lifetime of the system in the evaluation of $G H G_{\text {direct }}$, and corresponding to the operation period (years) in the case of $G H G_{\text {indirect }}$ evaluation.

- For PV-VCC:

$$
\begin{gathered}
G H G_{\text {direct }_{V C C}}=G W P\left[L \times n+\left(1_{V C C_{\text {unit }}} \times m\right)(1-\alpha)\right] \\
G H G_{\text {direct }_{V C C}}=293.15 \mathrm{~kg}_{C O_{2}} / \text { year } \\
G H G_{\text {indirect }_{P V}}=E_{P V} \beta \times n+G H G_{M_{V C C-P V}} \\
G H G_{\text {indirect }_{V C C}}=G H G_{M_{V C C}} \\
G H G_{\text {indirect }_{P V-V C C}}=43 \mathrm{~kg}_{C_{2}} / \text { year } \\
G H G=G H G_{\text {direct }_{V C C}}+G H G_{\text {indirect }_{P V-V C C}}
\end{gathered}
$$

$$
G H G_{P V-V C C}=336.3 \mathrm{~kg}_{\mathrm{CO}_{2}} / \text { year }
$$

- For the absorption and adsorption systems, the compression process of refrigerant is based on the heat supplied by solar thermal collectors in which $\mathrm{CO}_{2}$ emission is negligible. In these systems, the $\mathrm{CO}_{2}$ emitted is only related to the manufacturing and to GWP of the refrigerant, which is often negligible due to the thermodynamic properties of the used working pair such as silica gel/water and water/LiBr having $\mathrm{GWP}=0$.

$$
\begin{gathered}
G H G_{\text {direct }_{A B}}=G H G_{\text {direct }_{A D}}=0 \\
G H G_{\text {indirect }_{A B-E T C}}=n E_{A B-E T C} \beta_{A B-E T C}+G H G_{M_{A B-E T C}} \\
G H G_{\text {indirect }_{A D-E T C}}=n E_{A D-E T C} \beta_{A D-E T C}+G H G_{M_{A D-E T C}} \\
G H G_{\text {indirect }_{A B-E T C}}=n E_{A B-E T C} \beta_{A B-E T C}+G H G_{M_{A B-E T C}} \\
G H G_{\text {indirect }_{A D-E T C}}=n E_{A D-E T C} \beta_{A D-E T C}+G H G_{M_{A D-E T C}}
\end{gathered}
$$

where $E_{A B-E T C}$ and $E_{A D-E T}$ are the electrical energy consumed by the secondary components (pump, valve, sensors, etc.)

In our case:

$$
\begin{gathered}
G H G_{M_{A B-E T C}}=1 G H G_{M_{A B}}+8 G H G_{M_{E T C}} \\
G H G_{M_{A D-E T C}}=1 G H G_{M_{A D}}+9 G H G_{M_{E T C}} \\
E_{A B-E T C} \beta_{A B-E T C}=E_{A B} \beta_{A B}+8 G H G_{M_{E T C}} \\
E_{A D-E T C} \beta_{A D-E T C}=E_{A D} \beta_{A D}+9 G H G_{M_{E T C}} \\
G H G_{\text {indirect }_{A B}}=15.4 \mathrm{~kg}_{C O_{2}} / \text { year } \\
G H G_{\text {indirect }_{A D}}=19 \mathrm{~kg}_{\mathrm{CO}_{2}} / \text { year }
\end{gathered}
$$

As seen from Fig.4, the absorption-ETC system represents a minimum emission of $15.4 \mathrm{~kg} /$ year, lower than that of the adsorption-ETC system by $18.94 \%$ and that of the conventional system by $94.41 \%$.

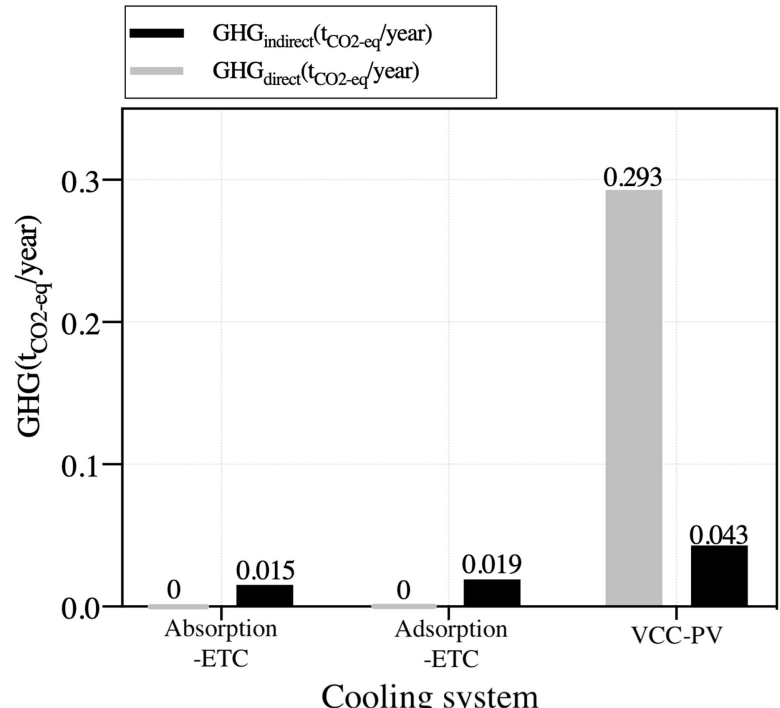

Figure 4. GHG emissions for each solar cooling system. 
The difference between the GHG emissions corresponding to the consumption of conventional electric energy based on fossil resources and the $\mathrm{CO}_{2}$ quantity emitted by each solar cooling system represents the avoided $\mathrm{CO}_{2}$ for each system, as shown in Fig. 5.

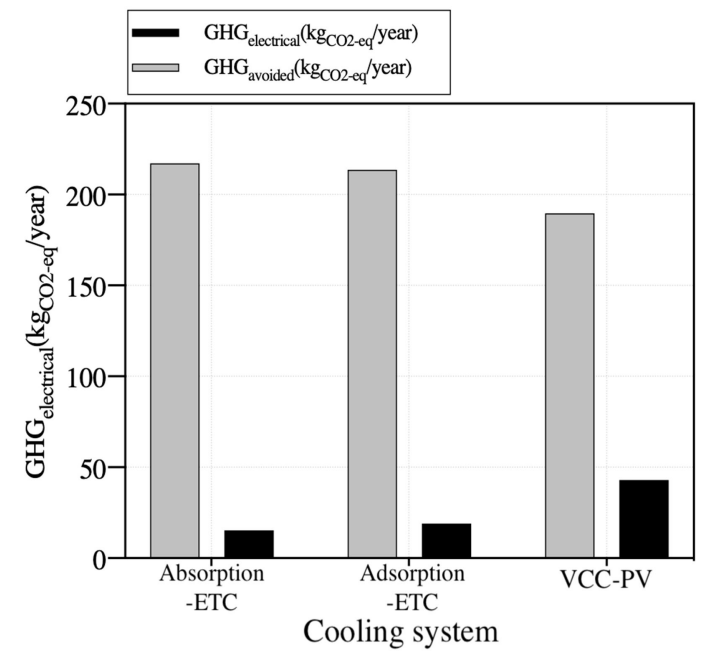

Figure 5. GHG emissions avoided for each cooling system.

\section{RESULT AND DISCUSSION}

The results obtained from the three compared systems are summarized in Table II, with consideration of the cooling capacity required to satisfy the building's cooling needs. According to Table II, the system that represents the high coefficient of performance is the conventional system powered by photovoltaic panels with a surface area occupied by the PV- panels much smaller than that of the evacuated tube collectors feeding the absorption and adsorption systems. For an annual cold production achieved using the three studied systems. The economic parameters are summarized in Fig. 6, which elucidates that the lowest average LCOE $(0.210 € / \mathrm{kWh})$ is obtained for conventional system driven by PV panels that is lower than that of absorption system by $14.97 \%$ and that of adsorption system by $19.84 \%$.

Moreover, the conventional system powered by PV panels has the lowest payback period of 5.84 year versus 7.12 year and 8.36 year for absorption-ETC and adsorption-ETC systems respectively. The payback period of the last system makes its choice unprofitable in the short term because of its higher investment cost and LCOE.

TABLE II. RESULTS FROM TECHNICAL-ECONOMIC AND ENVIRONMENTAL STUDY

\begin{tabular}{|c|c|c|c|}
\hline Cooling system & $\begin{array}{c}\text { PV- } \\
\text { VCC }\end{array}$ & $\begin{array}{c}\text { Absorption- } \\
\text { ETC }\end{array}$ & $\begin{array}{c}\text { Adsorption- } \\
\text { ETC }\end{array}$ \\
\hline COP & 3 & 0.8 & 0.69 \\
\hline $\begin{array}{c}\text { Cooling production } \\
\text { (kWh/year) }\end{array}$ & 972 & 972 & 972 \\
\hline $\mathbf{L C O E ~ ( € / k W h ) ~}$ & 0.210 & 0.247 & 0.262 \\
\hline $\begin{array}{c}\text { Maximal surface area of } \\
\text { solar collector (m) }\end{array}$ & 1.27 & 17.44 & 19.96 \\
\hline $\begin{array}{c}\text { Total GHG emissions of } \\
\text { the system }\left(\boldsymbol{t}_{\mathbf{c o}_{2-\text { eq }}} / \mathbf{y e a r}\right)\end{array}$ & 0.336 & 0.015 & 0.019 \\
\hline
\end{tabular}

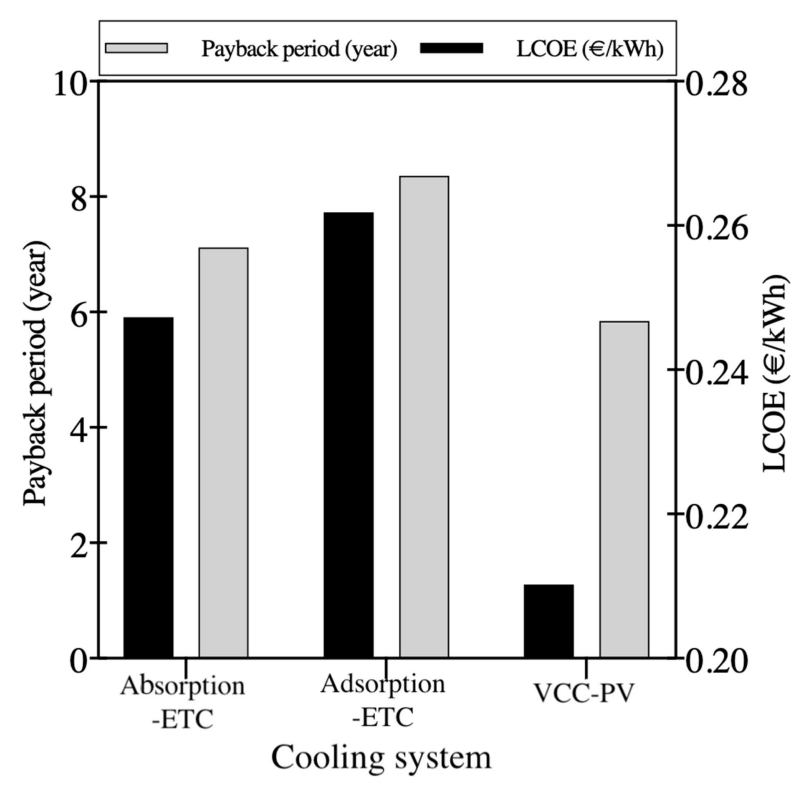

Figure 6. Economic indicators for each solar cooling system.

In terms of the environmental aspect, Table II shows that the two sorption systems are found to be better with a relatively low GHG emissions compared to the conventional system which emits an annual amount of $0.293 t_{\mathrm{CO}_{2-e q}}$ contributing to the global warming caused by the R134a used as refrigerant fluid, and an annual emission emitted by photovoltaic panels conversion equal to $0.043 t_{\mathrm{CO}_{2-e q}}$.

\section{CONCLUSION}

In this work, a comparative study was carried out for three types of solar cooling systems for a building located in Tangier city, Morocco. The main findings from this study were drawn as follows:

- The minimum levelized cost of cooling was found for the absorption cooling system driven by evacuated tube collectors because of the lower investment cost and its high coefficient of performance compared to the two other systems.

- In terms of environmental impact, the sorption (ad/absorption) cooling systems are more environmentally friendly due to the absence of greenhouse gas emissions. Furthermore, contrary to the compression cooling system powered by photovoltaic panels, they are silent due to the absence of moving device (compressor).

- Refrigerants used in conventional cycle represent the major disadvantage of being unsafe because most of them are flammable and toxic. 


\section{REFERENCES}

[1] La vérité sur les réserves mondiales », Yves Mathieu, Éditions Technique, Travaux de Roland Vially, géologue à IFPEN (2011).

[2] Chekirou Wassila. Etude et analyse d'une machine frigorifique solaire à adsorption (2008) 40-4.

[3] A. El Fadar. Novel process for performance enhancement of a solar continuous adsorption cooling system. Energy 114 (2016) 10-23.

[4] A. El Fadar. Thermal behaviour and performance assessment of a solar adsorption cooling system with finned adsorber. Energy 83 (2015) 674-684.

[5] I. Yildiz, B. Sosaoglu. Spatial distributions of heating, cooling and industrial degree-days in Turkey. Theoretical and Applied Climatology. 90, (2007) 249-261.

[6] European commission. Photovoltaic geographical information system. https://ec.europa.eu.

[7] Ahmed Hamza H. Ali. Performance-cost and global warming assessments of two residential scale solar cooling systems versus a conventional one in hot arid areas. Sustainable Energy Technologies and Assessments 20 (2017) 1-8.

[8] Medmenham. British Refrigeration Association, Guideline method of calculating TEWI, 1996.

[9] Nicholas J Santero, Arpad Horvath. Global warming potential of pavements. Environmental Research Letters. 23 September 2009.

[10] Aprea, A. Greco, A. Maiorino. An experimental evaluation of the greenhouse effect in the substitution of R134a with CO2 C. Energy 45 (2012) 753-761.

[11] ADEME. Documentation des facteurs d'émissions de la base carbone 2014. http://www.bilans-ges.ademe.fr.

[12] Vasilis M. Fthenakis, Hyung Chul Kim, Erik Alsema. Emissions from photovoltaic life cycles Environ. Sci. Technol. 2008, 42, 6, 2168-2174. 